\title{
AS METODOLOGIAS ATIVAS DIANTE DO ENSINO REMOTO: histórico e considerações teóricas para os anos iniciais do ensino fundamental
}

Adriano Hidalgo Fernandes - UEM adrianohidalgofernandes@gmail.com

Flávio Rodrigues de Oliveira - UEM froliveira3@uem.br

Maria Luisa Furlan Costa - UEM luisafurlancosta@gmail.com

\section{RESUMO}

Embora o conceito de Metodologias Ativas assuma um status de buzzword, é possível resgatar em sua história antecedentes que remontam à Antiguidade clássica, como por exemplo, o método socrático. Ainda assim, o maior destaque para essa abordagem teórica se dá a partir da primeira metade do século XX, com a tendência pedagógica tecnicista e os estudos sobre o construtivismo social, destacando-se principalmente pela crítica realizada aos modelos de educação tradicionais. Nesse sentido, o artigo em questão é de caráter bibliográfico e tem por base a análise histórica de como as Metodologias Ativas tornam-se uma possibilidade pedagógica a sociedade do século XXI. Em seguida, busca apresentar as principais abordagens dentro das Metodologias Ativas que podem ser utilizadas para 0 Ensino Remoto na quadratura atual, tendo em vista os anos iniciais do Ensino Fundamental. Discorremos também acerca da necessária formação de professores para atuar com as Tecnologias de Informação e Comunicação, a imprescindível passagem da educação tradicional para o processo de ensino e aprendizagem que contemple Metodologias Ativas, de modo a atender as novas habilidades demandadas pela sociedade vigente. Iniciativa, criatividade, autonomia, entre outros aspectos são essenciais que sejam desenvolvidos desde os anos iniciais do ensino fundamental. Verificamos diante do Ensino Remoto o quanto ainda estamos distantes de práticas educativas que contemplem metodologias ativas associadas as novas tecnologias educacionais.

Palavras-chave: Metodologias Ativas. História da Educação. Ensino Remoto.

ACTIVE METHODOLOGIES IN THE FACE OF REMOTE EDUCATION: history and theoretical considerations for the early years of elementary school

\section{ABSTRACT}

Although the concept of Active Methodologies assumes a buzzword status, it is possible to recover in its history antecedents that go back to classical antiquity, such as the 
Socratic method. Even so, the greatest emphasis on this theoretical approach occurs from the first half of the $20^{\text {th }}$ century, with the technical pedagogical trend and studies on social constructivism, standing out mainly for the criticism made to the traditional models of education. In this sense, the article in question is of a bibliographic character and is based on the historical analysis of how Active Methodologies become a pedagogical possibility for $21^{\text {st }}$ century society. Then, it seeks to present the main approaches within the Active Methodologies that can be used for Remote Education in the current framework, considering the initial years of Elementary Education. We also talked about the necessary training of teachers to work with Information and Communication Technologies, the essential transition from traditional education to the teaching and learning process that contemplates Active Methodologies, in order to meet the new skills demanded by the current society. Initiative, creativity, autonomy, among other aspects are essential to be developed since the early years of elementary school. It was observed, regarding Remote Education, how far we are still from educational practices that include active methodologies associated with new educational technologies.

Keywords: Active Methodologies. History of Education. Remote Teaching.

\section{LAS METODOLOGÍAS ACTIVAS ANTES DE LA EDUCACIÓN A DISTANCIA: historia y consideraciones teóricas para los primeros años de la educación fundamental}

\section{RESUMEN}

Aunque el concepto de Metodologías Activas asume un estatus de palabra de moda, es posible recuperar en su historia antecedentes que se remontan a la antiguedad clásica, como el método socrático. Aun así, el mayor énfasis en este enfoque teórico se da a partir de la primera mitad del siglo XX, con la corriente técnica pedagógica y los estudios sobre el constructivismo social, destacando principalmente por la crítica realizada a los modelos tradicionales de educación. En este sentido, el artículo en cuestión es de carácter bibliográfico y se basa en el análisis histórico de cómo las Metodologías Activas se convierten en una posibilidad pedagógica para la sociedad del siglo XXI. Luego, busca presentar los principales enfoques dentro de las Metodologías Activas que se pueden utilizar para la Educación Remota en el marco actual, considerando los años iniciales de Educación Primaria. También hablamos de la formación necesaria de los docentes para trabajar con las Tecnologías de la Información y la Comunicación, la transición imprescindible de la educación tradicional al proceso de enseñanza y aprendizaje que contempla las Metodologías Activas, con el fin de dar respuesta a las nuevas competencias que demanda la sociedad actual. La iniciativa, la creatividad, la autonomía, entre otros aspectos son fundamentales para desarrollarse desde 
los primeros años de la escuela primaria. Verificamos antes de Educación Remota lo lejos que estamos de prácticas educativas que incluyen metodologías activas asociadas a las nuevas tecnologías educativas.

Palabras clave: Metodologías activas. Historia de la educación. Enseñanza remota.

\section{INTRODUÇÃO}

É dos gregos a ideia de paideia, palavra que etimologicamente dá origem a Pedagogia se caracterizando por ser uma ciência que tem como princípio o estudo da Educação nas suas múltiplas relações do processo de ensino e aprendizagem. Pedagogo era naquele momento o escravo de guerra que acompanhavam as crianças que iam à escola e embora submissos às crianças, devido a classe que pertenciam, ainda assim, tinham de fazer-se valerem de uma certa autoridade quando os efebos se distanciavam do objetivo educacional. Deste modo, aos poucos esses paidagogos, foram adquirindo uma maior habilidade no trato com as crianças.

É dos gregos também a primeira referência histórica às metodologias ativas, não exatamente com este nome, mas como conceito. Sócrates, vem sendo para os mais clássicos, o pai das Metodologias Ativas. Por meio do método socrático, o interlocutor tomava voz em seu processo de reflexão autônoma. A ideia central do processo é instigar ideias próprias por meio da ironia e maiêutica. De acordo com Cortelazzo. et. al. (2018, p.92):

Sócrates (469-399 a.C.) expunha seus interlocutores a um processo de questionamento denominado maiêutica. Basicamente ele não ensinava diretamente, mas indiretamente por meio de perguntas. As perguntas direcionavam seus alunos (discípulos) a um itinerário formativo

Nesse sentido, ao se propor que as metodologias ativas trazem uma perspectiva de ensino focada no discente, podemos de fato ver em Sócrates uma linha histórica inicial para essa abordagem. Por meio do seu método, é possível perceber que nenhuma resposta era dada de antemão aos seus interlocutores, mas sim, criado no processo dialógico de reflexão compartilhada.

Partimos da premissa de que muitos professores dos anos iniciais do ensino fundamental não utilizam as metodologias ativas em suas aulas, sobretudo no ensino remoto, seja por estarem alicerçados ao modelo tradicional de ensino e aprendizagem, não terem conhecimento sobre como podem ser trabalhados os conteúdos de modo a contemplarem as metodologias ativas articuladas as novas tecnologias, entre outras questões. Destarte, faz-se necessário que o professor deixe de ser um mero transmissor de conhecimentos historicamente acumulados e passe a construir e aplicar metodologias que valorizem o protagonismo dos aprendizes no processo educacional. 
Mas embora resgatemos na Antiguidade clássica os antecedentes conceituais das Metodologias Ativas, será apenas no século XX que esta perspectiva se consolidará como um método crítico a um modelo passivo de aprendizagem. Tendo em vista a influência do filósofo americano John Dewey na evidência de que o ensino das habilidades de pensamento se tornava mais efetivo quando o sujeito torna-se partícipe do seu processo educacional, as Metodologias Ativas começam a se configurar no cenário educacional brasileiro. Sobre esse movimento do filósofo americano, Vickery (2016, p. 3) ressalta que:

Diversos programas que pretendem ajudar no desenvolvimento da habilidade
de pensamento foram desenvolvidos, levando em conta essas novas
evidências sobre o funcionamento do cérebro. Dewey (1938) está associado
a estruturas de reflexão em que os alunos são incentivados a refletir sobre o
processo de aprendizagem a fim de modificá-lo e aprimorá-lo. Também está
associado com a noção de educação experiencial

Passa-se a partir daí a valorizar a experiência do discente diante do aprendizado, tornando-se um referencial para uma educação mais efetiva diante de um modelo em que o educando apenas assimila as ideias e as reporta sem reflexão ativa. Essas ideias adentram o contexto brasileiro criando um movimento histórico chamado de Escola Nova amplificado, principalmente, pela publicação do Manifesto dos Pioneiros da Educação Nova (1932). Nas palavras de Cortelazzo et.al.(2018, p. 92):

No final do século XIX, o movimento da "Escola Nova" ou "Escola Ativa"que promulgava a libertação do educando da tutela exagerada dos seus professores, dando-lhe mais autonomia no próprio processo de aprendizagem, chegou ao Brasil pelas mãos de Rui Barbosa. O movimento inspirou e ganhou força após o Manifesto dos Pioneiros da Educação Nova, em 1932 e, após o estado Novo, novamente, nos Colégios de Aplicação mantidos pelas faculdades de filosofia das universidades brasileiras.

Esse movimento, ora mais, ora menos vem sendo evidenciado como uma perspectiva teórica mais efetiva dentro do cenário da educação do século $\mathrm{XXI}$, advinda de uma abordagem ainda mais tecnológica e dinâmica de espaços híbridos entre tecnologia e mundo analógico. Nesse novo ambiente, as gerações $Y$ e $Z$, muito mais tecnológicas do que as gerações $X$ e Baby Boomer requerem novas práticas de ensino e aprendizagem que sejam mais significativas e experienciais do que um ensino totalmente passivo.

O movimento mutatis mutandis altera significativamente os processos de formação de professores, tendo em vista um profissional que cria trilhas de aprendizagens compartilhadas, sendo no sentido clássico do termo, aquele que acompanha o percurso do discente, orientando e criando momentos e movimentos de aprendizagens. 


\section{AS METODOLOGIAS ATIVAS NO CONTEXTO DA EDUCAÇÃO DOS ANOS INICIAIS DO ENSINO FUNDAMENTAL}

Se fizer uma análise de todo o processo educacional desde os anos iniciais até os cursos de pós-graduação, é perceptível o quanto as metodologias ativas estão presentes no ambiente escolar dos anos iniciais. Calcados em uma visão experiencial de educação corroborados pelas teorias de Piaget e Vygotsky, o Ensino Fundamental I tem em seu bojo as metodologias ativas de aprendizagem como padrão de ensino. $\mathrm{E}$ de fato as crianças começam a aprendizagem como aprendizes poderosos, investigando e experimentando o mundo ao seu redor. Contudo, a medida em que os anos de formação vão se seguindo, os discentes tornam-se cada vez mais passivos do seu processo. Sobre esse processo inicial de aprendizagem nos anos iniciais do Ensino Fundamental, Vickery ( 2016, p. 22), assinala que:

\footnotetext{
Nada é tomado por garantido ou conhecido - tudo tem de ser descoberto desde o início. Quando as crianças chegam pela primeira vez no ambiente da educação infantil, elas são aprendizes fortes e experientes, acostumadas a aprender e a explorar por meio de seus sentidos, a fazer perguntas e a construir o seu próprio entendimento. Os professores da educação infantil têm o privilégio de trabalhar com uma turminha que quer saber, que quer entender e quer fazer.
}

Vemos assim, como a educação infantil está fortemente marcada de modo analógico pelos conceitos que perpassam as Metodologias Ativas. Nessa fase, mais do que em outras, o ensino requer, para se efetivar, diretamente da experiência com o mundo, de modo a assimilar e acomodar novos conceitos saindo de estágios operatórios concretos até chegar a estados de abstração de conceitos.

São inúmeras as possibilidades de aprendizagem por intermédio das metodologias ativas nos anos inicias dos Ensino Fundamental. Consideramos que nessa etapa da Educação Básica é imprescindível que sejam oportunizadas às crianças diferentes processos de aprendizagem, de modo que desenvolvam os aspectos sociais, afetivos e cognitivos. Nesse sentido, Moran (2018, p. 3) destaca que "A aprendizagem mais profunda requer espaços de prática frequentes (aprender fazendo) e de ambiente ricos em oportunidades". Não obstante, partimos da premissa que muitos docentes não utilizam as metodologias ativas no processo de ensino e aprendizagem por não terem conhecimento acerca das mesmas ou pelo fato de estarem na "zona de conforto" do ensino tradicional.

Partimos do pressuposto que algumas instituições escolares que ofertam os anos iniciais do ensino fundamental não propõem atividades práticas aos alunos no Ensino Remoto. Acabam por apenas disponibilizarem atividades que são realizadas da mesma forma que no ensino tradicional. O fato do ensino estar acontecendo de 
forma remota, de modo a utilizar ferramentas tecnológicas (Google Meet, Classroom, Zoom, etc) não significa que o processo tenha sido permeado por atividades práticas que desenvolvam a autonomia, criatividade, iniciática, entre outros aspectos que percebemos ser possíveis diante de metodologias ativas.

A sala de aula invertida, jogos educativos, visitas virtuais, desafios, aula expositiva dialogada, são algumas metodologias ativas que podem ser desenvolvidas nos anos iniciais do ensino fundamental.

Sobre a aula invertida, o professor pode, por exemplo, disponibilizar um vídeo previamente sobre determinado conteúdo para que o mesmo possa ser discutido, tratado na próxima aula. Essa metodologia ativa permite que o estudante tenha mais argumentos e propriedade no decorrer da aula. Acerca da aula invertida (flipped classroom), Valente ( 2018, p. 27). explicita que:

\footnotetext{
$\mathrm{Na}$ abordagem sala de aula invertida, o conteúdo e as instruções recebidas são estudadas on-line, antes de o aluno frequenta a aula, usando as TDIC, mais especialmente, os ambientes virtuais de aprendizagem. A sala de aula torna-se o lugar de trabalhar os conteúdos já estudados, realizando atividades práticas como resolução de problemas e projetos, discussão em grupo e laboratórios. No entanto, o fato de as atividades que o estudante realiza on-line poderem ser registradas no ambiente virtual de aprendizagem cria a oportunidade para o professor fazer um diagnóstico preciso do que o aprendiz foi capaz de realizar, as dificuldades encontradas, seus interesses e as estratégias de aprendizagem utilizadas. Com base nessas informações, o professor, juntamente com o aluno, pode sugerir atividades e criar situações de aprendizagens totalmente personalizadas.
}

Sobre a aula invertida no Ensino Remoto para os anos iniciais, julgamos que a referida metodologia pode acontecer com êxito, tendo em vista que o professor pode formar um grupo, no WhatsApp, por exemplo, para que os alunos estudem previamente e ser discutido, colocado em prática na aula remota que em muitas escolas têm sido realizada pelo Google Meet.

Há muitos jogos educativos disponíveis na internet que podem ser compartilhados, sugerido pelos professores aos seus alunos. É possível também que o professor elabore os jogos de acordo com as necessidades da turma.

Muitos espaços geográficos, obras de artes, etc., podem ser explorados por intermédio da internet. Assim sendo, os alunos podem fazer uma "visita" a diferentes lugares apenas com um clique.

Consideramos que os estudantes apreciam ser desafiados, estimulados a resolver problemas de diferentes situações. Para tanto, é importante que o professor os motive, instigue e os direcione. AAprendizagem Baseada em Problemas (ABP), em inglês, Problem- Based Learning (PBL) consiste em fazer com que o aluno aprenda a pesquisar novos conhecimentos por intermédio de diferentes recursos (SOARES; BOTINHA; NOVA; SOARES; BULAON, 2018, p. 107). 
No tocante a aula expositiva dialogada, o docente deve dar vez e voz aos seus estudantes, haja vista que a mera transmissão de conteúdos historicamente acumulados ao longo do tempo, ainda que importantes, não engendram novos conhecimentos. Coimbra (2018, p. 12) que "[...] a estratégia da aula expositiva dialogada apresentase como uma possibilidade real de estabelecer uma relação entre os aprendentes, incorporando componentes que farão parte do processo de ensinagem".

São inúmeras as possibilidades de metodologias ativas que são demasiadamente profícuas nos anos iniciais do ensino fundamental. Contudo, o sair do tradicional e ingressar nas metodologias ativas demanda muita criatividade por parte dos docentes.

Presumimos que há poucos cursos de formação direcionados aos professores, sobretudo dos anos iniciais, etapa que serve de base para a aquisição de novas habilidades ao longo da vida. No que tange ao conceito mais amplo da palavra mediação, Thadei (2018, p. 92) evidencia:

\begin{abstract}
Atualmente (re)afirmar que a postura do professor transmissor de informações deve dar lugar a postura de mediador entre o sujeito e o objeto de conhecimento parece ser redundante e insuficiente aos anseios daqueles que estão se tornando professores ou cuja formação acadêmica não favorece a prática pedagógica, sobretudo quando se trata do mundo contemporâneo. É comum e quase um jargão pedagógico a expressão professor mediador (ou apenas mediador) vinculada a relatos de práticas que se distanciam do verdadeiro sentido de mediação ou revelam uma compreensão rasa do conceito.
\end{abstract}

Destarte, quando tratamos sobre as metodologias ativas, não podemos deixar de discutir a necessária formação dos professores. Adentrar ao universo de um novo paradigma consiste em uma tarefa árdua, no entanto, possível quando os protagonistas da educação estão dispostos a romper com os modelos tradicionais de ensino e há investimentos em cursos de aperfeiçoamento, bem como incentivo para que os professores os realizem.

O uso positivo da informática em um ambiente educacional varia de acordo com a proposta utilizada em cada caso, a dedicação e o treinamento dos profissionais envolvidos. É importante que as pessoas que participam desses projetos estejam dispostas a encarar os novos desafios (TAJRA, 2019, p. 67).

Julgamos que os estudantes dos anos iniciais aprendem de forma exitosa realizando atividades práticas, ao invés de simplesmente realizar atividades impressas e que preconizam a memorização, sem que a criatividades e as habilidades específicas das crianças sejam explicitadas e potencializadas. A educação deve se adequar às novas exigências estabelecidas pela sociedade vigente, tais como: criatividade, autonomia, iniciativa. Nesse sentido, as metodologias ativas contribuem significativamente para que essas habilidades sejam desenvolvidas. 
As metodologias ativas constituem alternativas pedagógicas que colocam o foco no processo de ensino e aprendizagem no aprendiz, envolvendo-o na aprendizagem por descoberta, investigação ou resolução de problemas, Essas metodologias contrastam com a abordagem pedagógica do ensino tradicional centrado no professor, que é quem transmite as informações aos alunos (VALENTE, 2018, p. 27).

Consideramos que alguns professores atribuem a dificuldade de aprendizagem somente aos alunos. No entanto, em alguns casos, o fato destes não aprenderem pode se dar em virtude de como os conteúdos são desenvolvidos. A sociedade se transformou diante das novas tecnologias e, assim sendo, temos um novo perfil de estudantes. Nesse sentido, Tajra (2019, p. 48), “A inovação já é essencial para a sociedade atual, pois já somos dependentes de equipamentos e formas de comunicação específicas, que podem permitir o desenvolvimento ilimitado".

As tecnologias por si só não são capazes de garantir práticas exitosas no processo de ensino e aprendizagem. Faz-se mister que todos os envolvidos com a educação estejam engajados em implantar uma cultura digital.

A autora supracitada destaca que "Apesar do avanço tecnológico, nenhuma nova tecnologia substituirá a mais perfeita tecnologia humana. Se não usada de forma correta e com acompanhamento, a internet pode se tornar um problema" (TAIJRA, 2019, p.51). Destarte, o protagonismo do professor não deixará de existir, porém tornar-se-á basilar, ainda mais, o constante aperfeiçoamento no que tange às novas tecnologias $e$ metodologias de ensino.

De acordo com Kenski (2006, p. 23):

As novas tecnologias de informação e comunicação, caracterizadas como midiáticas, são, portanto, mais do que simples suportes. Elas interferem em nosso modo de pensar, agir, sentir, de nos relacionarmos socialmente e adquirirmos conhecimentos. Criam uma nova cultura e um novo modelo de sociedade.

Diante da pandemia da Covid-19, muitos professores tiveram que reinventar suas aulas, criar estratégias e se apropriarem de recursos tecnológicos capazes de dar continuidade aos conteúdos antes ministrados presencialmente. Todo esse cenário acabou por provocar um certo incômodo em alguns professores, haja vista a nova e necessária maneira de ensinar discutida, contudo, não colocada em prática.

No tocante a formação de professores no que diz respeito às Tecnologias Digitais (TD), Moreira; Schelemmer (2020, p. 27) anunciam:

Com efeito a mudança de paradigma e de filosofia educacional, para uma educação digital em rede, exige uma política ativa de formação docente, de apropriação digital, a fim de proporcionar a criação e o desenvolvimento de metodologias e práticas pedagógicas, mais coerentes com esse tempo histórico e social e que considerem as especificidades e potencialidades dos novos meios, a fim de propiciar acréscimo em termos de qualidade, por meio de programas de formação/qualificação com TD conectivas, nos quais cada um pode se transformar num co-produtor, contribuindo para fazer emergir novas ecologias educacionais. 
Discutimos muito sobre as tecnologias educacionais, contudo, por diversos fatores, o debate geralmente não engendra novas práticas pedagógicas por intermédio dos recursos digitais de que dispomos. Esses acabam sendo compreendidos tão somente como instrumentos de entretenimento. Desse modo, "a cultura do entretenimento", obrigatoriamente, deu lugar à cultura digital, momento em que o professor passou a ter que tomar decisões a curto prazo.

\section{METODOLOGIAS ATIVAS NA PERSPECTIVA DO ENSINO REMOTO PARA OS ANOS INICIAIS DO ENSINO FUNDAMENTAL}

Diante do isolamento social acarretado pela pandemia da Covid-19, o mundo evidenciou novas práticas pedagógicas, dentre elas, o Ensino Remoto que se tornou uma possibilidade para a continuidade do processo de ensino e aprendizagem de maneira virtual. Contudo, um problema tem se levantado quando se pensa os anos iniciais do Ensino Fundamental: como ensinar de modo Remoto para discentes que ainda não possuem uma literacia digital para a operacionalização das ferramentas tecnológicas? Obviamente, não é uma resposta que se encontre uma solução fácil, mas ainda assim é possível elencar elucubrações a fim de contribuir para os diálogos referentes a este momento histórico. Assim, o primeiro ponto que deve ser levado em consideração é esclarecer o que se compreende por Ensino Remoto.

Nesse sentido, Moreira e Schlemmer (2020) apresentam a definição de Ensino Remoto e/ou Aula Remota como o momento em que, devido a Covid-19, instituições de ensino do mundo inteiro migraram as aulas presenciais para plataformas virtuais de aprendizagem. Desse modo, refere-se a um momento específico datado historicamente, a saber, a primeira parte do ano de 2020 em que escolas de todo o mundo viram-se obrigadas a suspender as aulas presenciais. Dessas, algumas optaram pela Educação Remota. Nas palavras dos autores:

\footnotetext{
O Ensino Remoto ou Aula Remota se configura então, como uma modalidade de ensino ou aula que pressupõe o distanciamento geográfico de professores e estudantes e vem sendo adotada nos diferentes níveis de ensino, por instituições educacionais no mundo todo, em função das restrições impostas pelo COVID-19, que impossibilita a presença física de estudantes e professores nos espaços geográficos das instituições educacionais (MOREIRA, SCHLEMMER, 2020, p. 8).
}

Compreendido então a modalidade do Ensino Remoto, o problema volta a pairar: como ensinar de modo Remoto para discentes que ainda não possuem uma literacia digital para a operacionalização das ferramentas tecnológicas?

É preciso lembrar que embora as atividades remotas ocorram preferencialmente em plataformas virtuais, esse não é o único canal para que a Aula Remota ocorra, web apps como o whatsapp, textos impressos disponibilizados em instituições de ensino também 
devem ser colocados em pauta, quando nem todos possuem meios para acessarem os conteúdos de maneira síncrona. Desse modo, é preciso que o recurso esteja diretamente vinculado ao acesso discente. Quanto maior a gama de oferta em plataformas diferenciadas do material trabalhando, maior será a democratização do acesso ao conteúdo. Isso não significa dizer, entretanto, que o educador deva criar uma infinidade de materiais diferentes, mas sim que deve disponibilizar o material criado de modo diferente, sempre levando em conta a proposta de participação discente na aquisição do conteúdo.

Por isso, é importante que ao se planejar uma aula o docente tenha em mente que tipo de competência ele busca trabalhar e qual habilidade ele irá requerer que o discente utilize para a resolução daquele conteúdo. Mais detidamente, faz se necessário ter também diante das Aulas Remotas a Base Nacional Comum Curricular (BNCC) como parâmetro norteador da Educação Ativa.

\begin{abstract}
As metodologias voltadas para a aprendizagem consistem em uma série de técnicas, procedimentos e processos utilizados pelos professores durante as aulas, a fim de auxiliar a aprendizagem dos alunos. $O$ fato de elas serem ativas está relacionado com a realização de práticas pedagógicas para envolver os alunos, engajá-los em atividades práticas nas quais eles sejam protagonistas da sua aprendizagem. Assim, as metodologias ativas procuram criar situações de aprendizagem nas quais os aprendizes possam fazer coisas, pensar e conceituar o que fazem e construir conhecimentos sobre os conteúdos envolvidos nas atividades que realizam, bem como desenvolver a capacidade crítica, refletir sobre as práticas realizadas, fornecer e receber feedback, aprender a interagir com colegas e professor, além de explorar atitudes e valores pessoais (VALENTE, 2018, p.28).
\end{abstract}

Outra via para uma educação efetiva dentro dos anos iniciais do Ensino Fundamental é levar em conta uma participação efetiva dos responsáveis legais do educando. Mesmo diante de uma jornada de trabalho diária, é preciso que os responsáveis se dediquem um tempo para acompanhar como auxiliares no processo de mediação a educação dessas crianças, principalmente as que estão iniciando o processo de alfabetização analógica.

Paralelo a esse letramento impresso, é necessário que diante desse novo cenário, trabalhe-se o letramento digital, tendo em vista a aquisição de habilidades e competências dentro da Cultura Digital, promulgadas pela BNCC. De acordo com a Base cabe às instituições de ensino proporcionar momentos em que se valorize de modo crítico e ético as competências para uma educação digital, tendo em vista a ampla manifestação desses meios na formação formal, informal e/ou não formal dos discentes. Expressa-se então de acordo com o texto que:

Compreender, utilizar e criar tecnologias digitais de informação e comunicação de forma crítica, significativa, reflexiva e ética nas diversas práticas sociais (incluindo as escolares) para se comunicar, acessar e disseminar informações, produzir conhecimentos, resolver problemas e exercer protagonismo e autoria na vida pessoal e coletiva (BNCC, 2019, p. 9). 
Neste sentido, é imprescindível que, junto as habilidades e competências já habitualmente requeridas no processo de ensino e aprendizagem, a competência tecnológica seja colocada em evidência, principalmente, levando em consideração o momento específico em que estamos inseridos. Dito de outro modo, faz-se necessário a operacionalização e o letramento das ferramentas digitais, com o objetivo da promoção, compreensão e a incorporação de espaços, físicos, virtuais ou híbridos, refletindo sobre a aquisição da competência tecnológica de maneira reflexiva, crítica, ética, democrática e colaborativa. Acerca da importância das tecnologias de informação e comunicação a BNCC (2019, p.58) evidencia:

\begin{abstract}
As experiências das crianças em seu contexto familiar, social e cultural, suas memórias, seu pertencimento a um grupo e sua interação com as mais diversas tecnologias de informação e comunicação são fontes que estimulam sua curiosidade e a formulação de perguntas. O estímulo ao pensamento criativo, lógico e crítico, por meio da construção e do fortalecimento da capacidade de fazer perguntas e de avaliar respostas, de argumentar, de interagir com diversas produções culturais, de fazer uso de tecnologias de informação e comunicação, possibilita aos alunos ampliar sua compreensão de si mesmos, do mundo natural e social, das relações dos seres humanos entre si e com a natureza.
\end{abstract}

Assim sendo, na BNCC explicita-se a importância da apropriação das tecnologias da informação e comunicação pelas crianças como mecanismo de "leitura de mundo", interação, aquisição de novos conhecimentos, entre outras questões que consideramos essenciais na sociedade vigente: criatividade, criticidade, capacidade de argumentação etc.

\title{
4 CONSIDERAÇÕES FINAIS
}

Diante do exposto, vimos que embora os anos iniciais do Ensino Fundamental priorizem uma aprendizagem ativa, o isolamento físico iniciado pela Covid-19 fez com que essa abordagem fosse abalada, necessitando repensar mais uma vez o papel docente. Este agora integrado com as plataformas digitais deve buscar aliar a competência e as habilidades da Cultura Digital promulgadas pelas BNCC em todos os seus planejamentos de aula. Dessarte, sobre o Ensino Remoto é imprescindível que se tenha com muita clareza de qual abordagem ativa integrará o currículo e o conteúdo abordado.

O Ensino Remoto pode ser entendido como uma oportunidade de refletirmos sobre o quanto ainda precisamos avançar no processo de ensino e aprendizagem nos anos iniciais e demais etapas/ níveis da Educação. Para tanto, faz-se imprescindível que novos rumos sejam tomados no período pós-pandemia, o que demanda novas políticas públicas de incentivo à formação de professores e investimentos que possibilitem o acesso de todos aos recursos tecnológicos. 
Ainda que as tecnologias, por si só, não assegurem a qualidade da educação, quando bem planejadas, de modo a considerar a relevância da dimensão pedagógica poderá contribuir significativamente para que tenhamos um novo cenário educacional.

Vivenciamos um cenário, o da pandemia, em que fomos convocados a transformar nossas práticas educacionais. O aluno como protagonista dessa conjuntura social vigente não será o mesmo, passará a requerer dos docentes novas estratégias de aprendizagem que contemplem as tecnologias de informação e comunicação.

Julgamos que a pandemia foi um "divisor de águas" entre o processo de ensino tradicional para o inovador. Contudo, essa ruptura demandará o envolvimento de todos os protagonistas da educação a fim de que as novas tecnologias e as metodologias ativas estejam presentes nos anos iniciais do ensino fundamental, haja vista que o processo de ensino e aprendizagem nessa etapa da educação básica ainda tem como base o modelo tradicional em que os discentes são meros receptores de conhecimentos já consolidados e reproduzidos pelos docentes. Consideramos o protagonismo discente deve ser desenvolvido desde a mais tenra idade para que paulatinamente tenhamos um novo formato de ensino e aprendizagem.

\section{REFERÊNCIAS}

$\mathrm{BAClCH}$, L; MORAN, J. (org). Metodologias ativas para uma aprendizagem mais profunda: uma abordagem teórico-prática. Porto Alegre: Penso, 2018.

BRASIL. Base Nacional Comum Curricular (BNCC). Educação é a Base. Brasília, MEC/CONSED/UNDIME, 2017. Disponível em: 568 http://basenacionalcomum.mec. gov.br/images/BNCC_publicacao.pdf. Acesso em: 02 jun. 2020.

COIMBRA, L. M. A aula expositiva dialogada em uma perspectiva freireana. In: LEAL, A. E; MIRANDA, G, J; NOVA, C, C, P, S. (orgs). Revolucionando a sala de aula: como envolver os estudantes aplicando as técnicas de metodologias ativas de aprendizagem.

CORTELAZZO, A. L. et. al. Metodologias ativas e personalizadas de aprendizagem: para refinar o seu cardápio metodológico. Rio de Janeiro: Alta Books, 2018.

KENSKI, V. M. Eras digitais e ações abertas de ensino e formação: tecnologias e tempo docente. Campinas: Papirus, 2013.

MOREIRA, J. A.;SCHLEMMER, E. Por um novo conceito e paradigma de educação digital 'onlife'. Revista UFG, Goiás, v. 20, 2020. Disponível em: https://www.revistas. ufg.br/revistaufg/issue/view/2150.Acesso em: 13 jun. 2020. 
THADEI, J. Mediação e educação na atualidade: um diálogo com formadores de professores. In: BACICH, L; MORAN, J (org). Metodologias ativas para uma aprendizagem mais profunda: uma abordagem teórico-prática. Porto Alegre: Penso, 2018.

VALENTE, A. J. Metodologias ativas para uma educação inovadora. In: BACICH, L; MORAN, J (org). Metodologias ativas para uma aprendizagem mais profunda: uma abordagem teórico-prática. Porto Alegre: Penso, 2018.

VICKERY, A. (org.). Aprendizagem ativa nos anos iniciais do Ensino Fundamental. Tradução de Henrique de Oliveira Guerra. Porto Alegre: Penso, 2016.

\section{BIOGRAFIA DOS AUTORES}

ADRIANO HIDALGO FERNANDES - Graduado em Licenciatura Plena em Ciências e Pedagogia pela Universidade Estadual de Maringá (UEM), Mestre em Educação pela mesma instituição. Compõe o Grupo de Pesquisa GPEaDTEC da UEM coordenado pela Profa. Dra. Maria Luísa Furlan Costa. Atualmente é professor da rede estadual de ensino do Quadro Próprio do Magistério do Paraná.

FLÁVIO RODRIGUES DE OLIVEIRA-Licenciado em Filosofia e Mestre em Filosofia (2016) pela Universidade Estadual de Maringá. Doutorando em História pela Universidade Estadual de Maringá. Membro do Laboratório de Estudos Medievais (LEM). Compõe o Grupo de Pesquisa GEPEaDTEC da UEM coordenado pela Profa. Dra. Maria Luísa Furlan Costa.

MARIA LUISA FURLAN COSTA- Possui graduação em História pela Universidade Estadual de Maringá (1990), mestrado em Educação pela Universidade Estadual de Maringá (1997) e Doutorado em Educação pelo Programa de Pós-Graduação em Educação Escolar da Universidade Paulista Julio de Mesquita Filho - UNESP/ Araraquara - (2010). Atualmente é professora associada da Universidade Estadual de Maringá. Tem experiência na área de Educação, com ênfase em Educação a Distância e Tecnologias Educacionais, Grupo de Pesquisa em Educação a Distância e Tecnologias Educacionais (GPEaDTEC) cadastrado no CNPq.

Data de recebimento: 01/09/2020

Data de aprovação: 22/10/2020 